\title{
UNLOCKING COMPLEXITY: BIG SCIENCE PROJECT AND RESEARCH AGENDA
}

\author{
JOHN L. MOTLOCH \\ Sustainable Communities Institute LLC and Ball State University, USA.
}

\begin{abstract}
This paper begins with the Big History story of complexity emerging through cycles of innovation and co-adaptation and humanity's role in this story. It addresses the current compromised status of complex adaptive systems, and potential for complexity science to re-empower these systems. It calls for a Big Science Project and Research Agenda that addresses symptomatic problems and the causal problem of loss of system co-adaptation needed to sustain complexity. Due to urgency, it calls for research and implementation that simultaneously promotes collaboration and co-adaptation at the scale and speed needed, while also addressing today's profound problems and need to re-provision the planet and humanity for a sustainable future. The paper has a meta-level focus on re-empowering complex adaptive systems by closing life-cycle loops, increasing process-level biomimicry, and other actions that increase whole-system health and resilience. It calls for systemic change that includes optimizing the energy-water-food nexus, bio-remediating hydrocarbon residuals, re-empowering resource cycles, replacing fossil-fuel and chemical-based agriculture with clean energy produced organic food and human behavior that interconnects more deeply with the complex adaptive system. The paper proposes a global network of centers and institutes where people learn to thrive into the future by collaborating with complex adaptive systems. It addresses these education-research-demonstration centers for learning and research focused on generating, applying, managing, and diffusing knowledge to transform dysfunctional ecological and social landscapes into fully-functional complex eco-social systems.

Keywords: big history, big science, centers and institutes, co-adaptation, complex adaptive systems, EWF Nexus, knowledge system, unlocking complexity.
\end{abstract}

\section{COMPLEX SYSTEMS}

Complexity occurs as agents at one scale produce behavior that lies at a higher level of complexity. As complexity grows through immense numbers of cycles of innovation and co-adaptation, complex adaptive systems emerge as networks of dynamic interaction [1]. Ecologic and social systems are complex and adaptive, as is humanity and its intelligent technology systems.

Complex adaptive systems have the co-adapted complexity needed to use photons of light to form chemical bonds and the carbohydrates that provide structure and feedstock to photosynthesis and living systems. Complex adaptive systems use genetic- and epigenetic-influenced co-adapted behaviors of immense numbers of participants at all stages of life cycles to sustain high levels of chemical, energy and material flows and to regenerate bio-capacity at increasingly higher levels. Whether people see complex adaptive systems as the millennia of evolutionary development, as bounty bestowed through creation, or both; more and more people are becoming extremely concerned with the escalating impacts of humanity's living in ways that compromise the ability of complex systems to fully regenerate their bio-capacity. This paper seeks to help humanity live within planetary boundaries [2] so as to re-empower systems to fully regenerate bio-capacity while allowing all of humanity as parts of a complex adaptive system to thrive. 


\subsection{Complex systems and the nature of humanity}

Increasing inability of humanity to live within planetary boundaries and social foundations is driving change from fully-regenerating complex adaptive systems to systems that fail to sustain their biocapacity and provide a safe and just place for humanity [3]. The profound challenge today is to adapt human behavior as agents in complex adaptive systems to interconnect physical, biological, and cognitive agents and re-empower full-regeneration of safe and just complex adaptive systems. Some people also see a need to reconnect science and spirituality and refocus the discourse from a reductive ecology/creation debate to a discussion of evolving ecosystems and unfolding complexity. Through the science lens, profound system change challenges us to appreciate humanity's role in fully-functional, regenerating ecosystems. Through the spirituality lens, it challenges us to live humanely in virtuous life cycles and unfolding complexity.

\section{BIG HISTORY STORY}

Big History is the story of complex adaptive systems from the Big Bang to modernity; and humanity's role in this story. It is the story of dynamic tension promoting complexification through massive numbers of cycles of innovation and co-adaptation that empower higher levels of system functionality, interconnectedness, and bio-capacity. Some see this complexification to include three transformations: physical transformation of the Universe, biological transformation of Planet Earth, and conscious transformation of the noosphere [4,5]. Christian presents it as an eight-stage progression [6]. Both groups share appreciation of Big History as the story of the progression of complex adaptive systems.

\subsection{Story of complexification}

Swimme and Tucker see complexification as three transformations [4]. The first physically transforms the universe, with complexification powered by tension between expansion and collapse. The second transforms Planet Earth into living systems, with co-adapted behavior of massive numbers of participants at all stages of life cycles building and sustaining the planet's bio-capacity. The third on-going transformation of consciousness is seen by some to be driven by a universal need to know and understand [7] and by the dynamic tension, in the human mind, between individual and collective motivations $[8,9]$

\subsubsection{Story of humanity's role}

In this current chapter of Big History, the mind of modern man uses symbols, language and recorded history as collective memory which, unlike genetics and epigenetics, includes innovations that successfully co-adapt and those that do not. This cognitive transformation is currently progressing into its third tradition of human engagement. The first tradition - humanity living within local limits - included most of human history, with humanity living within limited local resources and struggling to enhance the human condition. In the second tradition - living unsustainably outside limits - technology and science combined to enable humanity to mine resources at ever-increasing scales, externalize costs, and thereby cause contextual system degradation at increasing scales and rates. In this tradition, people isolated themselves from many of the impacts of their behavior, and externalized these impacts to other people, places and species. Empowered at ever-increasing levels, this tradition impacted complex adaptive systems at accelerating rates and scales. Resulting system change now exposes the profound threat science and technology pose to humanity [10] and the urgent need to learn to live within the complex adaptive system that 
sustains us. This realization is driving the emerging third tradition - sustainable growth within global limits - as an appreciative system that relates to the reality it helps create [11]. This tradition is challenging humanity to engage the systems upon which we depend - especially those that regenerate clean air, pure water, and productive soils - in ways that sustain system complexity, health, and regeneration. It challenges humanity to internalize all costs so engagement re-empowers system health and complexity and allows regenerative systems at all scales from local to global to sustain full-functionality. It challenges us to transform the landscapes of reduced functionality produced by centuries of false belief that humanity could live outside systems into healthy, fullyregenerating ecosystems.

\subsubsection{Mapping the third transformation}

Beck and Cowan [12], Ken Wilbur [13] and others have mapped levels of bio-psycho-social complexity as frameworks of consciousness. These levels are seen herein as stages in the third transformation wherein humanity learns to live appreciatively in the complexity it helps create. Since symbolic memory includes innovations that co-adapt and those that do not, human systems evolved by the second tradition of living unsustainably outside systems are not self-managing. In this third stage of transformation, we are beginning to discover and appreciate the immense interconnectivity needed to sustain the complexity upon which humanity depends, and the urgent need to shift to conscious actions that help regenerate complexity beyond our ability to fully understand, much less replicate.

\subsubsection{Story of new potential}

Humanity is beginning to imagine the immense opportunity inherent in re-empowering complexity and re-provisioning humanity in ways that can trigger immense bio-capacity. This potential lies in emergent behavior, where agents at one scale produce behavior at a higher level of complexity. Building from Roger's diffusion of innovations work [14], Motloch [15] sees four stages of engaging any growth potential. Stage 1: Emergence occurs when innovations adapted to system conditions positively address the problems created by previous decisions; Stage 2: Growth occurs and accelerates as innovation produces positive system feedbacks, thereby encouraging and rewarding further growth. Stage 3: Maturity is reached as maximum sustainable growth is achieved and system feedback begins to shift from positive to negative. Stage 4: Decline occurs and accelerates as mainly negative system feedback discourages further engagement.

The contention herein is that humanity has progressed into the fourth stage of its living unsustainably platform based on fossil fuel consumption. Unsustainable growth empowered by reductive science, powerful technologies, and fossil fuel consumption have converted fully-functioning regenerative ecosystems into systems with less than full-functionality. Fossil fuel residuals, heavy metals, and other constituents are serving as roadblocks to emergence of new system complexity. For example, fossil fuel residuals in soils prevent thriving of the complex living systems these soils could otherwise support.

Ramo refers to the present as The Age of the Unthinkable [16]; and discusses how the new world order continues to surprise us as actions taken for seemingly good reasons have unthinkable consequences. Motloch and Truex [17] see these outcomes as the profoundly negative feedback of engagement using what is now an outdated and inappropriate development tradition that mines resources and produces wastes beyond the capacity of the system to regenerate its complexity and sustainable yield. The contention herein is also that this unique time in history is an age of immense new potential; and that this potential can begin to be realized when humanity again commits to living appreciably in complex adaptive systems. 


\section{BIG SCIENCE STORY}

Complexity science is the scientific study of complex adaptive systems whose parts interact to produce more-complex behavior [1]. Since Big History is the story of complexity through time, the scientific study of complexity is herein referred to as Big Science. Together Big History and Big Science, like Zukav's Dancing Wi-Li Masters [18] view of new physics, can help build the complexity science knowledge system for humanity to become an appreciate system that fully engages in the complex adaptive system that we help create.

\subsection{Complexity science knowledge system}

The current status of ecological and social systems as complex adaptive systems speaks to the urgent need to develop the complexity science knowledge system, including knowledge generation, application, management, and diffusion, needed to re-provision humanity to transform to sustainability. Building this knowledge system is a major shift from the science that empowered humanity with the ability to create today's profound problems that include but are not limited to pervasive poverty, global climate change, escalating crime, terrorism, nations on the verge of bankruptcy, and a myriad of other problems.

Building this knowledge system will require that we address complexity at three levels: object, system, and meta level. At the object-level, decisions will address immediate needs in ways that do not compromise complexity and interconnectedness. Interdisciplinary teams will investigate complex social and environmental problems and make appreciative decisions to address symptoms produced by previous unsustainable engagement, and will integrate their actions into complex systems while seeking to "do no harm". Object-level decisions will also be appreciative-ready, i.e., able to function in more appreciate future systems. At the system level, decisions will focus on whole-system complexity and functionality. Interdisciplinary teams will embrace diverse knowledge systems, broad awareness, and methodological flexibility to identify whole-system solutions and the complexity knowledge needed to function appreciatively. At the meta level, decisions will focus on relationships, conditions and processes that promote emergence of more appreciative system-level and object-level decisions. At this level interdisciplinary teams will focus on whole-systems, the synergy of diverse knowledge systems, process-level biomimicry, and embracing unknowns and uncertainty as agents of emergence rather than expressions of imperfection. Teams can use learning-forward strategies; and all fields of science can take ownership of integrating with complexity. Methods can avoid the specialized and self-referential nature of disciplines [19] and embrace interdisciplinary processes and team-generated solutions. Interdisciplinary teams can collaborate in centers or institutes as homes for emergence [20] using new administrative structures [21] and enhanced network information flow using transdisciplinary and team science approaches [22, 23] that re-provision universities [24] in ways that re-empower complex adaptive systems to fully-regenerate, co-adapt and complexify.

\section{BIG SCIENCE PROJECT}

To jump-start this new complexity science knowledge system, humanity needs a Big Science Project on the scale and urgency of the Genome Project. This Project will seek to build the knowledge system needed to empower humanity to live appreciatively within the complex adaptive system it helps create. The Project will be grounded in innovation and co-adaptation; and an understanding of the meta-problem of increasing inability of systems to co-adapt, fully function, and fully regenerate. As a complex adaptive system, this knowledge system can grow from small seeds in diverse domains, seeing what works and what doesn't, and co-adapting things that work within domains into a complex adaptive system. 
The Big Science project will target the causal problem, seek to reverse the trend of reduced complexity and inability to co-adapt; and endeavor to build the understanding of complexity needed to empower humanity to co-adapt at the scale and speed needed. It will seek to optimize the ability of the current system to address complex problems, and facilitate emergence of the new system that produces less new problems. This complexity science knowledge system will focus on innovation [25] and co-adaptation. Due to the nature and urgency of the challenge, and need to re-provision concurrently with enhancing performance within existing provisioning, both thrusts will occur simultaneously.

\subsection{Emergent status of the big science project}

On-going initiatives around the world, if seen as a mosaic, look like the beginning of this Big Science Project, complete with a research agenda beginning to unfold as the nexus of several dimensions of complexity. In terms of governance complexity, the Widening Circle action campaign and related Global Citizens' Movement for a Great Transition [26] has identified principles that can inform proposals for world governance [27]. In terms of social complexity, the Network Nation collaborative project seeks to address concerns about social fragmentation and partisanship, and what is seen as chronic gridlock in governance. The Next System Project [28] is positioned within this nexus of complexity as part of Widening Circle 2.0 [29]; and as the Collaborative Backbone on the Next Nation [30]. In terms of development complexity, the Internet of Things and smart technologies offer immense ability to sense, store, interconnect and communicate the immense data needed to coadapt, unlock complexity, empower the circular economy [31] and unlock full-spectrum capitals [32] to re-empower complexity.

As this Complexity Science Big Science Project continues to emerge, it can do so with governance appropriate for unlocking complexity. This governance can embrace principles similar to those of the Forum for a New World Governance that include power framed by the people being governed and sustained by a shared perception that decisions address individual and collective needs so as to promote an ethical, just society. They can include civility that builds a sense of shared destiny, excludes tyranny by individual or majority, and balances rights, powers, and responsibility. They can help provision society for competent and effective public and private institutions responsive to all needs of a diverse society; and embrace collaboration and co-adapted behavior among the full diversity of public and private entities, so governance helps sustain the commons. They may also embrace justice at all scales so societies from local to global can organize themselves and operate in ways compatible with social cohesion at all scales. [33]

\subsection{Big science research agenda}

Developing the complexity science knowledge system will require a massive action research agenda to generate, apply, manage and diffuse complex adaptive system knowledge. This agenda will embrace the co-adaptation needed to empower homeostasis, self-organization, and complexification; and can help humanity address today's myriad of symptomatic problems and, more importantly, the causal problem of growing inability of systems to co-adapt and fully-regenerate. This agenda can also focus on helping humanity collaborate with complexity; and co-adapt at the scale and speed needed to re-empower complexity; so humanity can address today's problems while re-provisioning economic and community development for a sustainable future.

This research agenda can integrate diverse knowledge systems - science, indigenous, vernacular, etc. - with a meta-level focus on re-empowering complex adaptive systems by closing life-cycle 
loops, increasing process-level biomimicry, enhancing fertility, accelerating ecological processes, empowering homeostatic, and increasing whole-system health and resilience. It can include systemlevel research focused on feeding good bacteria and starving bad, bio-remediating industrial hydrocarbon chains that have accumulated in systems, dissipating residuals, re-empowering resource cycles including nitrification, and replacing fossil-fuel powered chemical-based agriculture with clean energy-based, locally-grown organic, healthy food. Much research can occur within a global network of centers and institutions where people learn to thrive by collaborating with complex adaptive systems [34]. These centers can have an integrated training, research, and demonstration action agenda focused on how humanity can live within complexity. This action agenda can help build the complexity science knowledge system for generating, applying, managing, and diffusing knowledge that can transform dysfunctional ecological and social landscapes into fully-functional complex eco-social systems.

\section{DESIGN SCIENCE ROLE IN COMPLEXITY SCIENCE}

Design science will play a major role in the action agenda to address today's profound challenge for humanity to live within its fully-functional complex adaptive system. To serve this role, design science can sustain its focus on innovation and quickly embrace co-adaptation that completes each cycle needed for complexity. As such, design science can also play a major role in the nexus of design science, transdisciplinary team science, and complexity science [35].

Design science can inform decisions integrated with complexity to build ecological, physiological, and psychological health. Grounded in complexity science, design science can engage systems at the object, system, and meta levels. At the object level, projects can address local system needs. System level engagement can include management frameworks that set limits and provide guidance to object-level decisions. Meta-level decisions can pursue relationships, conditions and processes that promote transformation to sustainability. Design science can also embrace innovative models for inter-professional dynamics to make sustainable resource management decisions, while addressing the needs for specific projects. By so doing, design science can help integrate decisions made by many people with differing motives. It can help interdisciplinary teams integrate diverse systems ecological, cultural, structural, infrastructural, visual, and economic - for maximum environmental and human wellness; and to help make appreciate decisions about the earth and its integrated systems [36].

In these and other ways, design science can play a major role in helping build the knowledge system - generation, application, management, and diffusion - needed to sustain interconnected energy, water, and food systems: the EWF Nexus. It can also play a major role in helping society replace the fossil fuel consumption that locks-up living systems with clean energy systems that use information encoded in the genetics and epigenetics of living systems. It can promote healthy water systems where water at all stages in life cycle addresses the needs of the diverse living and non-living components needed for full-functionality and regeneration of complexity. Finally, it can provide the vision needed to replace the current non-appreciative decisions that assault complex systems with dirty energy, contaminated water, unhealthy food, and disinformation with appreciative ones that ensure that all voices - human, other living, and non-living - needed for full-functionality and regeneration are heard.

\subsection{Design science research}

Rather than only targeting today's myriad of symptoms - climate change, species loss, organized crime, diverging incomes, failing states, etc. - design science research can also focus on the causal 
problem, i.e., loss of ability of systems to sustain complexity due to inadequately co-adapted behavior. It can seek to reverse the growing inability of complex adaptive systems to sustain co-adaptation of parts and behaviors, full-functionality, regeneration, and ability to coordinate behaviors in ways that sustain the capacity of the complex adaptive system. It can build understanding of the nexus of design science, team science and complexity science to empower whole-system functionality, coadaptation and regeneration. It can help build understanding of how knowledge from diverse theories such as rapid co-adaptation theory [37] and relevant frameworks such as whole-system Indicator frameworks, can empower and accelerate co-adaptation of human behavior at the scale and speed needed to re-empower complex systems so humanity can thrive as part of these systems [33].

To help address the causal problem, application-focused design science action research can extend the time humanity has to become appreciative by increasing humanity's performance in addressing complex adaptive system needs, while accelerating the shift needed to re-empower complexity and avoid creating new complex problems. Furthermore, due to severity of the problem and urgency of the challenge, it can do both simultaneously and as quickly as possible. By so doing design science, as a subset of Big Science linked with Big History's unfolding complexity, can play a crucial role in the Big Science Project.

\section{6 "UNLOCKING COMPLEXITY” AS GOAL OF BIG SCIENCE PROJECT}

As stated earlier, fossil fuel residuals, heavy metals, and other impacts are often roadblocks to emergence of system complexity. For example, fossil fuel residuals lock-up agricultural soils and ecological systems, preventing them from supporting complex living systems. There is a profound need for this Big Science project and research agenda to focus on Unlocking Complexity; and for the complexity science knowledge system to re-provision global society in ways that promote coadaptation, homeostasis, and self-organization. There is also the need to address symptoms and, most importantly, mitigate the causal problem of growing inability of systems to co-adapt and build complexity. This Unlocking Complexity Big Science Project and Research Agenda can build the knowledge system needed to unlock complex adaptive systems so they can build the complexity needed to move beyond their current condition that places humanity at profound risk. This Big Science Project will, of necessity, extend beyond unlocking ecologic complexity to unlocking cognitive complexity.

\subsection{Unlocking ecological complexity}

This Big Science Project and Research Agenda can include initiatives focused on unlocking ecologically complexity, closing life-cycle loops and increasing process-level biomimicry. It can include action items to empower para-magnetics and fertility, accelerate ecological processes, and reempower homeostatic and self-regulation. It can include system-level initiatives to feed good bacteria and starve bad, bio-remediate industrial hydrocarbon chains that have accumulated in systems, dissipate residuals, re-empower resource cycles including nitrification, and replace fossil-fueled chemical-based agriculture with clean energy-produced organic food. By these and other actions, it can build whole-system health and resilience.

\subsection{Unlocking cognitive complexity}

This Big Science Project and Research Agenda can focus on unlocking the cognitive complexity arrested by the false belief that humanity could live outside systems, mine resources at everincreasing scales, and externalize costs without profound consequences. Most recently cognition 
has been further arrested by culturally induced ignorance or doubt based on inaccurate or misleading scientific data. Unlocking this arrested consciousness can allow humanity to appreciate complexity beyond our current ability to understand; and to build the knowledge system needed to sustain healthy regeneration of all essential and interconnected systems. It can empower an appreciative humanity to use information to sustain clean and healthy energy, water, and food systems; and replace the fossil fuel consumption that locks-up living systems with clean energy systems that use information encoded in the genetics and epigenetics of living systems. It can empower healthy water systems where water conditions at all stages in life cycles address the needs of the diverse living and non-living components needed for full-functionality and regeneration. It can also empower implementation of healthy local and slow food systems that provide the food and fiber needed to support whole-system functionality and regeneration. In doing so, the Unlocking Complexity Big Science Project can replace the non-appreciative mindset and hierarchical communication strategies that assault complex adaptive systems with dirty energy, water, food, and disinformation with appreciative humanity that uses network conversation to ensure all voices - human, other living, and non-living - needed for full-functionality and regeneration are heard.

\subsubsection{Global network of centers and institutes}

There is a need for a global network or centers and institutes focused on unlocking complexity by building bridges between community development and the nexus of energy, water and food, as well as the nexus of design science, transdisciplinary team science, and complexity science. These centers and institutes can help humanity co-adapt at the scale and speed needed to re-empower the complex adaptive systems of which they are part. These centers can pursue the following principles of the Sustainable Communities Institute as triggers for building resilient, thriving communities [38]. The first is to live within the systems upon which people depend to sustain ecological, social, and economic prosperity. The second is to promote whole-system solutions that address the needs of people and the systems upon which they rely. The third is to build whole-system knowledge and the diversity of knowledge systems. The fourth is to engage all sectors to build shared-consciousness and the collective-will to be sustainable. The fifth is to collaborate among local and global experts to benefit from the full diversity of knowledge. The sixth is to build the full-spectrum of capitals needed to optimize whole-system health, prosperity, and growth.

In these centers and institutes, people can learn to thrive into the future by collaborating with complex adaptive systems. Each center can help people learn to live with system limits including optimizing the local food-water-energy nexus and re-provisioning communities to engage food, water and energy in ways that sustain people, place and prosperity. These can be education-researchdemonstration centers for learning to live within complexity, build interconnectivity, and help transform dysfunctional ecological and human landscapes into fully-functional complex and coadapted eco-social systems.

The heart of each of these centers can be integrated water-energy-food systems that produce more food for less money than traditional farming practices and that can grow food year round. They can produce fresh, healthy and great-tasting natural and organic food via an eco-friendly, green system that uses clean energy, conserves water and reduces waste [39]. In these centers, people can learn to use these systems and local food production to provide quality food, conserve water, and build economic opportunity, while removing agriculture loads from land areas to allow these areas to return to serving their vital role in the complexity of Planet Earth. Each can transform hydrocarbons into food for existing bacteria, allow these bacteria to better serve their role in complexity: and convert waste to food. They can transform benzene chains in soil into food for bacteria in the soil [40] to 
convert fossil fuel residuals that currently lock-up agricultural soils into food for bacteria in living systems so these bacteria can unlock the soil and provide healthy food for the complex web and food chains of complex systems.

The intent herein is that as education-research-demonstration centers for learning to live within complexity, each center is also a key participant in the Big Science Project and Research Agenda and action agenda to build the complex adaptive system knowledge system needed to unlock complexity.

\section{REFERENCES}

[1] Johnson, S., Emergence: The Connected Lives of Ants, Brains, Cities, and Software, Scribner, 2002.

[2] Rockström, J., Planetary Boundaries: Exploring the Safe Operating Space for Humanity, The Reliance Center, 2009.

[3] Raworth, K., A Safe and Just Space for Humanity: Can we Live Within the Doughnut? Oxfam International Discussion Paper, 2012.

[4] Swimme, B.T. \& Tucker, M.E., Journey of the Universe, Yale University Press, 2011.

[5] Teilh.ard de Chardin, P., The Phenomenon of Man, Harper Torchbooks, 1961.

[6] The History of our World in 18 Minutes, David Christian, TED2011, available at www.ted. com/talks/david_christian_big_history?language=en

[7] Maslow, A.H. \& Lowery, R. (ed0073), Toward a Psychology of Being, 3rd edn., New York: Wiley \& Sons, 1998.

[8] Graves, C.W., 'Meet Mr. Graves' spiraldynamics.org/2012/06/meet-dr-graves/

[9] Wilbur, K., A Theory of Everything: An Integral Vision for Business, Politics, Science and Spirituality, Shambhala Pub. Inc: New York, 2000.

[10] Humanity is going to use science and technology to wipe itself out, S.W. Hawking, available at www.independent.co.uk/news

[11] Jantsch, E., Design for Evolution, Braziller Publisher: New York, 1975.

[12] Beck, D.E. \& Cowan, C., Spiral Dynamics: Mastering Values, Leadership, and Change, Blackwell Publishing Ltd., 1996.

[13] Wilbur, K., A Theory of Everything: An Integral Vision for Business, Politics, Science and Spirituality, Shambhala Pub. Inc: New York, 2000.

[14] Rogers, E.M., Diffusion of Innovations, 5th edn., Simon \& Schuster, 2003.

[15] Motloch, J.L., Facilitating Social and Economic Change, Symposium to Increase Community Prosperity in the New Economy, Ball State University, 2012.

[16] Ramo, J.C., The Age of the Unthinkable: Why the New World Disorder Constantly Surprises Us and What We Can Do About It, Little, Brown and Company Pub., 2009.

[17] Motloch, J.L. \& Truex, S.I., Complexity Science and Architecture in the. University of the Future 2nd International Conference on Social Housing and Sustainability, PUCRS, Brazil, 2012.

[18] Zukav, G., The Dancing Wu Li Masters: An Overview of the New Physics, William Morrow and Company pub., 1979.

[19] Bursztyn, M. \& Maury, M.B., The Brazilian experience with institutional arrangements for interdisciplinary graduate programs: I2S may provide a new way (Chapter 43). Disciplining Interdisciplinarity: Integration and Implementation Sciences for Researching Complex RealWorld Problems, ed. G. Bammer, ANU E Press, 2013.

[20] Cram, L., Building I2S into an academic program (Chapter 41). Disciplining Interdisciplinarity: Integration and Implementation Sciences for Researching Complex Real-World Problems, ed. G. Bammer, ANU E Press, 2013. 
[21] Nellis, M.D., Moving competitive integrated science forward: a US land grant university perspective (Chapter 46). Disciplining Interdisciplinarity: Integration and Implementation Sciences for Researching Complex Real-World Problems, ed. G. Bammer, ANU E Press, 2013.

[22] Lefroy, T., Interdisciplinary research is about people as well as concepts and methods (Chapter47). Disciplining Interdisciplinarity: Integration and Implementation Sciences for Researching Complex Real-World Problems, ed. G. Bammer, ANU E Press, 2013.

[23] Falk-Krzesinski, I2S and research development professionals: time to develop a mutually advantageous relationship (Chapter 58). Disciplining Interdisciplinarity: Integration and Implementation Sciences for Researching Complex Real-World Problems, ed. G. Bammer, ANU E Press, 2013.

[24] Withers, G., Creating the new university, (Chapter 8). Disciplining Interdisciplinarity: Integration and Implementation Sciences for Researching Complex Real-World Problems, ed. G. Bammer, ANU E Press, 2013.

[25] Elsum, I., tackling integrated applied research: lessons from the management of innovation (Chapter 55). Disciplining Interdisciplinarity: Integration and Implementation Sciences for Researching Complex Real-World Problems, ANU E Press, ed. G. Bammer, 2013.

[26] Global Citizens Movement, available at www.kosmosjournal.org/programs/global-citizensmovement/

[27] Principles of Governance: A Guide to Developing Proposals for World Governance, available at www.world-governance.org/article152

[28] Democracy Collaborative; available at www.democracycollaborative.org/.

[29] Widening Circle 2.0, available at www.wideningcircle.org/ProgramPhase1/Index.html

[30] Network Nation, available at www. Networknation.net

[31] Intelligent Assets, Unlocking the Circular Economy Potential, Ellen Macarthur Foundation, 2016.

[32] Armistead, D., Symposium on Community Social and Economic Change in the New Economy, Ball State University, Muncie IN, 2011.

[33] Forum for a New World Governance, available at www.world-governance.org/article152

[34] Motloch, J.L., Living within humanity's life-support system. International Conference on Sustainable Design Engineering and Construction, 2015.

[35] Motloch, J.L., Review: G. Bammer (ed.): Disciplining Interdisciplinarity. Journal of Environmental Studies and Science, 2015.

[36] Motloch, J.L., Introduction to Landscape Design, 2nd edn., John Wiley \& Sons, Inc., 2000.

[37] "Rapid Evolutionary Adaptation: Potential and Constraints". ERACAPS Plant Science Database, available at eracaps-psd.org/node/988

[38] Sustainable Community Institute, available at www.facebook.com/sci.thrive/

[39] ECSIA, Environmentally Controlled Integrated Sustainable Agriculture, available at www. ecsia.us/

[40] Fog Free Technologies, available at www.fogfreetechnologies.com 